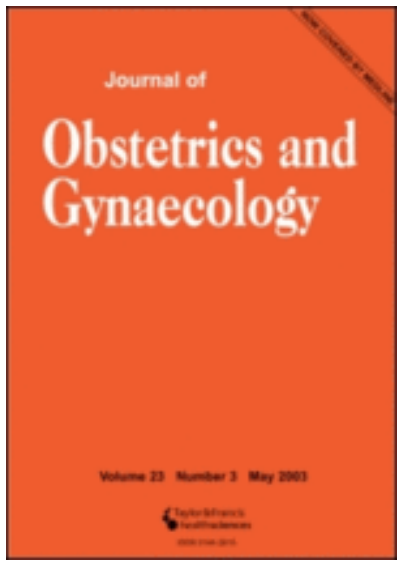

\title{
Patient Costs and Outcomes Before and After the Institution of a Preeclampsia Quality Improvement Initiative in a Southwestern Tertiary Facility
}

\begin{tabular}{|c|c|}
\hline Journal: & Journal of Obstetrics and Gynaecology \\
\hline Manuscript ID & CJOG-2018-0528.R1 \\
\hline Manuscript Type: & Original Article \\
\hline $\begin{array}{r}\text { Date Submitted by the } \\
\text { Author: }\end{array}$ & 05-Nov-2018 \\
\hline Complete List of Authors: & $\begin{array}{l}\text { Banke-Thomas, Aduragbemi; Dignity Health Medical Group Arizona, } \\
\text { Centre for Women's Health; Arizona State University, McCain Institute } \\
\text { for International Leadership; London School of Economics and Political } \\
\text { Science, Health Policy } \\
\text { Rosser, Casey; University of North Carolina, Obstetrics and Gynaecology } \\
\text { Brady, Robert; Dignity Health Medical Group Arizona, Centre for } \\
\text { Women's Health } \\
\text { Shields, Laurence; Dignity Health, Patient Safety; Marian Regional } \\
\text { Medical Centre }\end{array}$ \\
\hline Keywords: & General obstetrics, Intrapartum care \\
\hline
\end{tabular}

\section{SCHOLARONE Manuscripts}




\title{
Patient Costs and Outcomes Before and After the Institution of a Preeclampsia Quality Improvement Initiative in a Southwestern Tertiary Facility
}

Running head: Costs and Outcomes of a Pre-eclampsia Quality Improvement Initiative

\author{
Authors and affiliations: \\ Aduragbemi Banke-Thomas 1,2,3*, Casey Rosser ${ }^{4}$, Michael Brady ${ }^{1}$, and Larry Shields ${ }^{5,6}$. \\ ${ }^{1}$ Centre for Women's Health, St. Joseph's Hospital and Medical Centre, Phoenix, Arizona, \\ United States of America. \\ ${ }^{2}$ McCain Institute for International Leadership, Arizona State University, Phoenix, Arizona, \\ United States of America. \\ ${ }^{3}$ Department of Health Policy, London School of Economics and Political Science, London, \\ United Kingdom. \\ ${ }^{4}$ Department of Obstetrics and Gynaecology, University of North Carolina, Chapel Hill, North \\ Carolina, United States of America. \\ 5 Maternal-Foetal Medicine, Marian Regional Medical Centre, Santa Maria, California, United \\ States of America. \\ ${ }^{6}$ Department of Patient Safety, Dignity Health, San Francisco, California, United States of \\ America.
}

\section{Corresponding author:}

Aduragbemi Banke-Thomas

Centre for Women's Health

St. Joseph's Hospital and Medical Centre, 
350 W Thomas Road,

Phoenix, AZ 85013.

USA.

Telephone: 602-344-5407

E-mail: a.bankethomas@asu.edu 


\section{Impact statement}

- What is already known on this subject? In 2013, the California Maternal Quality Care Collaborative (CMQCC) set up a task force to develop guidelines for managing patients with preeclampsia based on global best practices. A previous study showed that despite system-level implementation challenges, the initiative led to significant increase in blood pressure treatments within one-hour and reduced severe maternal morbidity.

- What do the results of this study add? This study follows patients from admission, beyond the one-hour post-treatment and into the post-partum phase, to understand if outcomes of the initiative extend beyond the admission. While the study findings do not show any statistically significant difference in readmission before and after the initiative, nor any marked difference in maternal outcomes, it shows a significant difference in the prevalence of stillbirths at no additional cost to the patient.

- What are the implications of these findings for clinical practice and/or further research? Based on these findings, there is a case for scaling-up the initiative as in addition to its evidenced improvements in maternal outcomes; it is effective in improving newborn health outcomes at no additional cost. Further research, using larger sample size and exploring different care levels would be useful to verify these findings.

Key words: Pre-eclampsia; hypertension; pregnancy; safety; quality collaborative; quality improvement 


\section{Introduction}

Globally, preeclampsia is one of the leading causes of pregnancy-related morbidity and mortality (Say et al. 2014). The condition is associated with increased risks of preterm delivery, intra-uterine growth restriction, placental abruption and perinatal mortality (Conde-Agudelo et al. 2000; Zhang et al. 2000; Goldenberg et al. 2008; Ananth and Basso 2010). Some authors have described pre-eclampsia as a "sentinel marker" for women who will develop chronic cardiovascular conditions following delivery (Irgens et al. 2001). Women with pre-eclampsia have an increased risk of future hypertension, ischemic heart disease and stroke (Bramham et al. 2013). In the United States, with an estimated prevalence of 3.8\% in 2010 (Ananth et al. 2013), pre-eclampsia is responsible for $17 \%$ of all maternal deaths that occur. However, $50 \%-$ $70 \%$ of such deaths are deemed preventable (MCAH 2012).

In 2013, the California Maternal Quality Care Collaborative (CMQCC) set up a task force made up of a multi-disciplinary team of experts, working in both high and low-volume obstetric units. They were tasked to develop tools and guidelines for managing patients with preeclampsia based on global best practices in diagnosis and management of preeclampsia (CMQCC 2013). The quality improvement initiative required early detection of preeclampsia with blood pressure (BP) confirmation within 15 - 20 minutes, if $\mathrm{BP}>160 / 110 \mathrm{mmHg}$, provider notification, the institution of treatment (based on evidence-based algorithms) within one-hour of BP confirmation including seizure prophylaxis with Magnesium Sulphate (Figure 1). Further recommendations include a follow-up appointment within 3-7 days if anti-hypertensive medication was used during labour and delivery or postpartum or within 7 - 14 days if no antihypertensive medication was used. The initiative also requires standardised patient education (CMQCC 2013). 
Previous studies that assessed the effectiveness of the initiative in reducing severe maternal morbidity (SMM) were based on a process indicator of time to institute treatment and immediate outcome indicator of the persistence of severe maternal morbidity one-hour after the institution of treatment (Shields et al. 2015; 2017). However, no study had explored the effect of the initiative on the cost of care and outcomes that occur beyond this one-hour posttreatment phase, despite the known fact that complications of preeclampsia can extend even beyond delivery and into the six-week post-partum period (Matthys et al. 2004). Our study objective was to evaluate the effectiveness of the CMQCC initiative as implemented in a tertiary hospital on associated patient costs and outcomes during the intrapartum and postpartum periods.

\section{Materials and methods}

A quasi-experimental design was used for this study. This design has been selected because it was not logistically feasible and unethical to conduct a randomised controlled trial, which is generally regarded as the "gold standard" of causal research design (Morgan et al. 2000; Harris et al. 2006), since women with preeclampsia cannot be denied of care they require upon presentation.

\section{Study setting}

This study was conducted in St. Joseph's Hospital and Medical Centre (SJHMC) hospital, which is managed by a non-profit organisation, Dignity Health. In 2014, the organisation embedded the CMQCC pre-eclampsia initiative as practice across all its hospitals including SJHMC, where about 5,000 births occur annually.

\section{Data collection}


Existing secondary data was mined for this research with coded data from a six-month precollaborative baseline period compared to prospectively reported outcomes of a six-month follow-up period, one-year after the CMQCC implementation. The coded intrapartum data was mined from the patient database (Midas ${ }^{\circledR}$ ) and additional post-partum data collected from patient records (as this could not be mined in Midas ${ }^{\circledR}$ ). Microsoft Excel (Microsoft Corporation, Redmond, California, USA) was used as a repository for the secondary data, collating the data in such a way it was easily retrievable.

All women, 18 years and above, who had conditions that could be classed under the relevant International Classification of Diseases (ICD)-10 codes for pre-eclampsia as recommended by experts (Callaghan et al. 2014) and captured on the Midas platform (Supplemental file 1) and who presented in the hospital within either study phase (baseline and follow-up) were included in the study.

Data on the pregnancy characteristics and relevant pre-existing conditions, intrapartum care and outcomes as well as outcomes reported during the post-partum period was collected. Using a unique patient medical record number (anonymised), we gathered pregnancy-related data focused on gestational age on admission (term vs. pre-term), number of foetuses (singleton vs. multiple gestation), delivery method, admission date, delivery date and discharge date (the latter three variables were used to estimate admission to delivery and admission to discharge period).

Also, we collected data on pre-existing conditions such as obesity and chronic hypertension. Intrapartum care data included data on the course of treatment, including the time and date for the initial episode of BP trigger $(>160 / 100 \mathrm{mmHg})$ and treatment regimen given to the patients. 
The data on any complications of pre-eclampsia which had been reported during the hospitalisation, included eclampsia, stroke, post-partum haemorrhage, pulmonary oedema, renal insufficiency (Creatinine $>1.1 \mathrm{mg} / \mathrm{dL}$ or double in a woman with already high creatinine) and liver injury (Twice normal high of Aspartate transaminase $[\mathrm{AST}]=68 \mathrm{IU} / \mathrm{L}$ and Alanine transaminase $[\mathrm{ALT}]=110 \mathrm{IU} / \mathrm{L}$ ) were also collected. In addition, we collected data on the cost of intrapartum care (only direct hospitalisation costs that included hospitalisation stay, medicines, and provider costs were included) and the payer for the care received (Self/Commercial/Medicaid/Medicare/Others). Post-partum period data captured included data on follow-up appointment time frame, BP after delivery, readmission history in the hospital for post-partum pre-eclampsia.

We used a comprehensive standardised operating procedure manual and ethical guidelines to support data collection. To quality-assure the data collection process, the investigators were competent in quantitative research with previous experience and significant training as well as trained in good clinical practice and data management, which was recently updated. Also, data was rechecked for completeness, accuracy and to avoid any errors which could bias analysis.

\section{Data analysis}

Following data collation in Microsoft Excel, the completed data sheet was exported to STATA 13.0 SE (Stata-Corp., College Station, Texas, USA), for analysis. Cost and outcome in a sixmonth pre-collaborative baseline were compared to the prospectively reported outcomes of the six-month follow-up period, one year after implementation of the initiative. The rationale for the choice of this one-year gap between the baseline and follow-up in the research is based on the $85 \%$ uptake of the protocol at this point. We argued that such a high percentage uptake would make outcome attributed to the initiative more sensible. 
Descriptive statistics with percentages were used to describe the demographic characteristics of the women included in the study. Chi-square test was used in comparing the proportion of outcomes at baseline with the one-year follow-up period, as this was categorical data. For cost, which is a continuous variable, the Student t-test comparison of two means was used for the analysis. Results were presented in tables with odds ratio, confidence intervals and $p$-values. A significance level of $p<0.05$ was used to confirm if there were any statistically significant differences in costs and outcomes between the baseline and follow-up periods.

We followed the most up-to-date SQUIRE (Standards for Quality Improvement Reporting Excellence) publication guidelines (Version 2.0) in reporting our study (Ogrinc et al. 2015).

\section{Ethical considerations}

The four key moral principles in conducting ethically sound research - autonomy, beneficence, non-maleficence, and justice (Beauchamp and Childress 2008), formed the ethical foundations of this study. All efforts to uphold the dignity of participants, to preserve their anonymity, confidentiality and protection against psychological harm were implemented through data collection, management and storage. Permission to access the database containing patient information was approved by the institutional review board (IRB) of the Dignity Health System (Ref \#: 010764). The data within Midas was already de-identified. However, for data that needed to be collected outside Midas, only the principal researcher had access to patient names. The combined database created did not include any attributable data to the included patients. The data was secured on the researchers' computers, was password protected and was not stored in any online/cloud storage. 


\section{Results}

One hundred and eighty-nine women met the inclusion criteria for this study, with 93 women included in the baseline period (before the initiative) and 96 women included in the follow-up period. Of the 93 women in the baseline group, $70(75 \%)$ had been classified as obese while 63 $(66 \%)$ of the 96 women in the follow-up group had been classed obese $(p=0.15)$ (Table I). Fifteen (16\%) and $21(22 \%)$ women in the baseline and follow-up group respectively had preexisting chronic hypertension by the time of hospitalisation $(p=0.32)$ (Table I).

Regarding the pregnancy, $2(2 \%)$ and $5(5 \%)$ in the baseline and follow-up group respectively were pregnant with more than one foetus $(p=0.27)$ (Table I). While $43(46 \%)$ in the baseline and $50(52 \%)$ in the follow-up group were term (37 weeks 0 , as defined by the American College of Obstetrics and Gynaecology (ACOG Committee on Obstetric Practice Society of Maternal-Fetal Medicine 2013)) at the time of admission $(p=0.42)$ (Table I). At delivery, 52 $(56 \%)$ and $59(62 \%)$ were delivered by Caesarean in the baseline and follow-up arm of the study, respectively $(p=0.44)$ (Table I).

There was no significant difference in the pre-eclampsia complications between the baseline and follow-up, except for stillbirth $(p=0.027)$ (Table II). In a multivariate analysis, there was an $87 \%(95 \%$ CI $0.06-0.92 ; p=0.027)$ decrease in the odds of having a stillbirth in the follow-up phase compared to the baseline (Table III). When adjusted for obesity, the adjusted odds ratio was estimated at $0.11(95 \% \mathrm{CI} 0.13-0.88 ; p=0.027)$ (Table III).

For the continuous variables, though the mean cost of hospitalisation was about $\$ 14$ higher, this was not statistically significant (Table IV). Similarly, there was no statistically significant difference in admission-delivery and admission-discharge periods (Table IV). However, there 
was a significant difference in duration of follow-up appointment following discharge $(p<0.01)$, with mean days being estimated as approximately 13 and 7 days respectively for baseline and follow-up periods (Table IV).

\section{Discussion}

In this quasi-experimental study, we evaluated the effectiveness of the CMQCC preeclampsia treatment initiative on patient costs and outcomes. Our findings showed that in a tertiary hospital setting, there was no significant difference in maternal health outcomes. However, there was a significant difference in newborn health outcomes with almost $90 \%$ reduction in odds of babies being born as stillbirths following the uptake of the initiative compared with baseline. There was also a significant reduction in the number of days between discharge and follow-up appointments. Regarding the care costs, similarly, there was no significant change in cost after the initiative was implemented. As in other collaborative assessments (Main et al. 2017), the groups used in this study for the baseline and follow-up periods were comparable as there was no significant difference in pregnancy characteristics and pre-existing conditions.

In a previous evaluation of the initiative, the authors found that compliance with utilisation of intravenous blood pressure medication increased by $33.2 \%(p<0.01)$ and utilisation of Magnesium Sulphate increased by $10.8 \%(p<0.01)$ during the six months of monitoring following the implementation of the initiative. In addition, incidence of eclampsia and total severe maternal morbidity (SMM) decreased by $42.6 \%(p<0.01)$ and $1.7 \%(p<0.01)$ respectfully (Shields et al. 2017). The former outcome change is a 'process' outcome, while the latter is a clinical outcome. While process outcomes demonstrate the evidence-based best practices that represent a health system's efforts to systematise its improvement efforts, clinical outcomes represent the changes that patient's experience (Mant 2001; Rademakers et al. 2011). 
Both have their value, however, indicators for tracking clinical outcome can be particularly useful in standardised data collection methods and when the occurrence of the outcome is sufficiently common that the outcome indicator will have the power to detect real differences in quality (Mant 2001). While standardised data collection procedures were instituted in this study, the outcome did not occur sufficiently enough to allow our analyses to pick the "real" differences. For example, we found no statistically significant differences in maternal outcomes that occurred before and after the initiative. While this may be due to the high standard of care expected in a tertiary hospital such as the one evaluated in this study, it could also be because of the relatively small sample size, especially as an earlier study conducted on a larger scale showed significant differences in SMM before and after the initiative was implemented (Shields et al. 2017). As such, the null difference finding in our study needs to be interpreted with caution. However, our study clearly showed that the initiative had been fully embedded in the hospital with a highly significant reduction in the number of days between discharge and follow-up visits comparing the number of days women had to wait for follow-up appointments before and after the initiative $(p<0.01)$. This is a process indicator that demonstrates uptake of the initiative within the facility.

One of the findings that had not been previously reported in the literature was a significant reduction in stillbirths in the follow-up period compared with the baseline. This significant reduction remained even after controlling for obesity. Pre-eclampsia is firmly associated with stillbirth (Conde-Agudelo et al. 2000; Ananth and Basso 2010; Smith 2015) and as evidenced in this study, clear guidelines in treating patients with the condition help to reduce associated mortalities with the unborn child. 
One other key finding the absence of a cost difference between the baseline and follow-up periods. As such, the benefits of the initiative are not coming at a significant cost to the patients. In our study, we estimated costs at $\$ 1,589.23$ at baseline and $\$ 1,607.36$ during the Follow-up. A previous estimate of the short-term costs associated with pre-eclampsia per birth at 36 weeks of gestational age were at $\$ 1,311.00$ (Stevens et al. 2017). As the study was based on data from 2012 (Stevens et al. 2017) and our study was based on data from the 2015 - 2016 period, it is possible to attribute the observed difference to inflation.

One of the key strengths of this study was that it leveraged a robust electronic health system that had standardised obstetric data definitions (Menard et al. 2014). While this study offers unique insight regarding the effectiveness of the CMQCC quality initiative, it is important to recognise the limitations that we have identified. We did not collect race/ethnicity data, especially as the impact of race/ethnicity on hypertensive diseases of pregnancy (Fridman et al. 2014). Furthermore, this study was based in a tertiary hospital. While facility based assessments like this provide some unique insight for quality improvement (Callaghan et al. 2014), there may be different explanations as to why there are observed variations in obstetric services in different levels of care (Main 2015). With the singular facility assessed, there was also a limit to the sample size that could be achieved in the study. There is certainly a case for conducting this research on a larger scale while capturing more facilities including different levels of care facilities. This would allow for more study power to assess effect of confounders.

\section{Conclusion}

Scaling-up the uptake of the CMQCC quality improvement initiative in health facilities is a worthwhile venture, as along with its already evidenced effect on improving maternal health 
outcomes in larger scale studies, we found that it contributes to reduction in stillbirths. These outcomes are achieved at no increase in hospitalisation cost for women with preeclampsia.

Acknowledgements: The authors are immensely grateful to Roxanne Genovese, the perinatal safety specialist at SJHMC for her immense support during the data collection phase of this study.

Funding: ABT was on a fellowship funded by the McCain Institute for International Leadership during the conduct of this research.

Declaration of interest statement: The authors report no conflict of interest. 


\section{References}

ACOG Committee on Obstetric Practice Society of Maternal-Fetal Medicine. 2013. Definition of Term Pregnancy. Obstetrics and Gynecology, 122 (5): 1139-1140.

Ananth CV and Basso O. 2010. Impact of pregnancy-induced hypertension on stillbirth and neonatal mortality. Epidemiology, 21 (1): 118-23.

Ananth CV, Keyes KM, Wapner RJ. 2013. Pre-eclampsia rates in the United States, 19802010: age-period-cohort analysis. BMJ, 347: f6564.

Beauchamp TL and Childress JF. 2008. Principles of biomedical ethics. 6th ed. USA: Oxford University Press.

Bramham K, Nelson-Piercy C, Brown MJ, Chappell LC. 2013. Postpartum management of hypertension. BMJ, 346: 8994.

Callaghan WM, Grobman WA, Kilpatrick SJ, Main EK, D’Alton M. 2014. Facility-based identification of women with severe maternal morbidity: it is time to start. Obstetrics and Gynecology, 123 (5): 978-81.

CMQCC. 2013. Improving Health Care Response to Preeclampsia: A California Quality Improvement Toolkit. Los Angeles.

Conde-Agudelo A, Belizan JM, Diaz-Rossello JL. 2000. Epidemiology of fetal death in Latin America. Acta Obstetricia et Gynecologica Scandinavica, 79 (5): 371-378.

Fridman M, Korst LM, Chow J, Lawton E, Mitchell C, Gregory KD. 2014. Trends in maternal morbidity before and during pregnancy in California. American Journal of Public Health, 104 (Suppl 1): S49-57.

Goldenberg RL, Culhane JF, Iams JD, Romero R. 2008. Epidemiology and causes of preterm birth. The Lancet, 371 (9606): 75-84. 
Harris AD, McGregor JC, Perencevich EN, Furuno JP, Zhu J, Peterson DE, et al. 2006. The use and interpretation of quasi-experimental studies in medical informatics. Journal of the American Medical Informatics Association, 13 (1): 16-23.

Irgens HU, Reisaeter L, Irgens LM, Lie RT, Lie RT. 2001. Long term mortality of mothers and fathers after pre-eclampsia: population based cohort study. BMJ, 323 (7323): 1213-7.

Main EK. 2015. Clues for understanding hospital variation among obstetric services. American Journal of Obstetrics and Gynecology, 213 (4): 443-444.

Main EK, Cape V, Abreo A, Vasher J, Woods A, Carpenter A, et al. 2017. Reduction of severe maternal morbidity from hemorrhage using a state perinatal quality collaborative. American Journal of Obstetrics and Gynecology, 216 (3): 298.e1-298.e11.

Mant J. 2001. Process versus outcome indicators in the assessment of quality of health care. International Journal for Quality in Health Care, 13 (6): 475-480.

Matthys LA, Coppage KH, Lambers DS, Barton JR, Sibai BM. 2004. Delayed postpartum preeclampsia: an experience of 151 cases. American Journal of Obstetrics and Gynecology, 190 (5): 1464-1466.

MCAH. 2012. The California Pregnancy-Associated Mortality Review (CA-PAMR): Report from 2002 - 2004 Maternal Death Reviews. Los Angeles.

Menard MK, Main EK, Currigan SM. 2014. Executive Summary of the reVITALize Initiative: standardizing obstetric data definitions. Obstetrics and Gynecology, 124 (1): 150-153.

Morgan GA, Gliner JA, Harmon RJ. 2000. Quasi-experimental designs. Journal of the American Academy of Child and Adolescent Psychiatry, 39 (6): 794-6.

Ogrinc G, Davies L, Goodman D, Batalden P, Davidoff F, Stevens D. 2015. SQUIRE 2.0

(Standards for QUality Improvement Reporting Excellence): revised publication guidelines from a detailed consensus process. American Journal of Medical Quality, 30 (6): 543-9. 
Rademakers J, Delnoij D, de Boer D. 2011. Structure, process or outcome: which contributes most to patients' overall assessment of healthcare quality? BMJ Quality and Safety, 20 (4): $326-31$.

Say L, Chou D, Gemmill A, Tunçalp Ö, Moller A.-B, Daniels J, et al. 2014. Global causes of maternal death: A WHO systematic analysis. The Lancet Global Health, 2 (6): e323-e333. Shields L, Kilpatrick S, Melsop K, Peterson N. 2015. Timely assessment and treatment of preeclampsia reduces maternal morbidity. American Journal of Obstetrics and Gynecology, 212 (1): S69.

Shields LE, Wiesner S, Klein C, Pelletreau B, Hedriana HL. 2017. Early standardized treatment of critical blood pressure elevations is associated with a reduction in eclampsia and severe maternal morbidity. American Journal of Obstetrics and Gynecology, 216 (4): 415.e1-415.e5.

Smith GC. 2015. Prevention of stillbirth. The Obstetrician and Gynaecologist, 17 (3): 183-187. Stevens W, Shih T, Incerti D, Ton TGN, Lee HC, Peneva D, et al. 2017. Short-term costs of preeclampsia to the United States health care system. American Journal of Obstetrics and Gynecology, 217 (3): 237-248.e16.

Zhang J, Troendle J, Levine R. 2000. Risks of hypertensive disorders in the second pregnancy. Obstetrics and Gynecology, 95 (4): S77. 
Table I. Characteristics of pregnancy and pre-existing conditions

\begin{tabular}{lllr}
\hline & Baseline $(\mathrm{n}=93)$ & Follow-up $(\mathrm{n}=96)$ & $p$ value \\
\hline Obesity & $70(75.3 \%)$ & $63(65.6 \%)$ & 0.15 \\
Chronic hypertension & $15(16.1 \%)$ & $21(21.9 \%)$ & 0.32 \\
Multiple gestation & $2(2.2 \%)$ & $5 .(5.2 \%)$ & 0.27 \\
Term pregnancy & $43(46.2 \%)$ & $50(52.1 \%)$ & 0.42 \\
Caesarean delivery & $52(56.0 \%)$ & $59(61.5 \%)$ & 0.44 \\
\hline
\end{tabular}


Table II. Bivariate analysis of categorical outcome data

\begin{tabular}{|c|c|c|c|c|}
\hline Outcome & Total $(\mathrm{N}=189)$ & Before & After & $p$ value \\
\hline \multicolumn{5}{|l|}{ Readmission } \\
\hline Yes & 13 & $6(6.5 \%)$ & $7(7.3 \%)$ & 0.820 \\
\hline No & 176 & 87 (93.5\%) & $89(92.7 \%)$ & \\
\hline \multicolumn{5}{|l|}{ Eclampsia } \\
\hline Present & 3 & $2(2.2 \%)$ & $1(1.0 \%)$ & 0.542 \\
\hline Not present & 186 & $91(97.8 \%)$ & 95 (99.0\%) & \\
\hline \multicolumn{5}{|c|}{ Cerebro-vascular accident } \\
\hline Present & 1 & $0(0.0 \%)$ & $1(1.0 \%)$ & 0.324 \\
\hline Not present & 188 & $93(100.0 \%)$ & 95 (99.0\%) & \\
\hline \multicolumn{5}{|c|}{ Post-partum haemorrhage } \\
\hline Present & 23 & $11(11.8 \%)$ & $12(12.5 \%)$ & 0.888 \\
\hline Not present & 166 & $8288.2 \%)$ & $84(87.5 \%)$ & \\
\hline \multicolumn{5}{|c|}{ Acute kidney injury } \\
\hline Present & 7 & $2(2.2 \%)$ & $5(5.2 \%)$ & 0.266 \\
\hline Not present & 182 & $91(97.8 \%)$ & 91 (94.8\%) & \\
\hline \multicolumn{5}{|l|}{ Liver injury } \\
\hline Present & 27 & $13(13.9 \%)$ & $14(14.6 \%)$ & 0.905 \\
\hline Not present & 162 & $80(86.0 \%)$ & $82(85.4 \%)$ & \\
\hline \multicolumn{5}{|l|}{ Birth status } \\
\hline Still birth* & 8 & $7(7.5 \%)$ & $1(1.0 \%)$ & 0.027 \\
\hline Live birth & 181 & $86(92.5 \%)$ & 95 (99.0\%) & \\
\hline
\end{tabular}

*Significant variable $p<0.05$ 
Table III. Logistic regression analysis

\begin{tabular}{|c|c|c|c|c|}
\hline Outcome & $\begin{array}{l}\text { Crude odds ratio } \\
\text { with } 95 \% \mathrm{Cl}\end{array}$ & $p$ value & $\begin{array}{l}\text { Adjusted odds ratio } \\
\text { with } 95 \% \mathrm{Cl}\end{array}$ & $p$ value \\
\hline \multicolumn{5}{|l|}{ Readmission } \\
\hline Yes & - & - & - & \\
\hline No & - & - & - & \\
\hline \multicolumn{5}{|l|}{ Eclampsia } \\
\hline Present & - & - & - & \\
\hline Not present & - & - & - & \\
\hline \multicolumn{5}{|c|}{ Cerebro-vascular accident } \\
\hline Present & - & - & - & \\
\hline Not present & - & - & - & \\
\hline \multicolumn{5}{|c|}{ Post-partum haemorrhage } \\
\hline Present & - & - & - & \\
\hline Not present & - & - & - & \\
\hline \multicolumn{5}{|c|}{ Acute kidney injury } \\
\hline Present & - & - & - & \\
\hline Not present & - & - & - & \\
\hline \multicolumn{5}{|l|}{ Liver injury } \\
\hline Present & - & - & - & \\
\hline Not present & - & - & - & \\
\hline Birth status & & & & \\
\hline Still birth & $0.13(0.06-0.92)$ & 0.03 & $0.11(0.13-0.88)$ & 0.04 \\
\hline Live birth & 1.00 & 8 & 1.00 & \\
\hline
\end{tabular}

Table IV. Two-sample t test with equal variances for continuous variables 


\begin{tabular}{|c|c|c|c|c|c|c|c|}
\hline Variable & Group & Mean & Std. Error & Std. Dev & {$[95 \% \mathrm{Co}$} & Interval] & $p$ value \\
\hline Hospitalisation & Baseline & $1,589.23$ & 68.36 & 659.22 & 1453.47 & 1724.99 & 0.8323 \\
\hline cost & Follow-up & $1,607.36$ & 51.91 & 508.60 & 1504.31 & 1710.41 & \\
\hline $\begin{array}{l}\text { Admission to } \\
\text { delivery period }\end{array}$ & Baseline & 3.14 & 0.14 & 1.37 & 2.86 & 3.42 & 0.3142 \\
\hline differentials & Follow-up & 3.34 & 0.14 & 1.41 & 3.05 & 3.63 & \\
\hline $\begin{array}{l}\text { Admission to } \\
\text { discharge period }\end{array}$ & Baseline & 4.66 & 0.25 & 2.43 & 4.15 & 5.16 & 0.3542 \\
\hline differentials & Follow-up & 4.99 & 0.26 & 2.5 & 4.48 & 5.59 & \\
\hline $\begin{array}{l}\text { Follow-up } \\
\text { appointment } \\
\text { from discharge }\end{array}$ & Baseline & 13.19 & 1.16 & 11.17 & 10.89 & 15.49 & 0.0000 \\
\hline differentials* & Follow-up & 6.84 & 0.38 & 3.72 & 6.09 & 7.59 & \\
\hline
\end{tabular}

Cost in US\$. All women included in the analysis (93 at baseline and 96 at follow-up).

*Significant variable $p<0.05$ 


\section{Supplemental material 1. ICD-10 codes included in analysis}

\begin{tabular}{ll}
\hline Codes & Description of condition \\
\hline 11.1 & Pre-existing hypertension with pre-eclampsia, first trimester \\
11.2 & Pre-existing hypertension with pre-eclampsia, second trimester \\
11.3 & Pre-existing hypertension with pre-eclampsia, third trimester \\
11.9 & Pre-existing hypertension with pre-eclampsia, unspecified trimester \\
14.1 & Severe pre-eclampsia, unspecified trimester \\
14.12 & Severe pre-eclampsia, second trimester \\
14.13 & Severe pre-eclampsia, third trimester \\
14.2 & HELLP syndrome, unspecified trimester \\
14.22 & HELLP syndrome, second trimester \\
14.23 & HELLP syndrome, third trimester \\
15 & Eclampsia in pregnancy, unspecified trimester \\
15.02 & Eclampsia in pregnancy, second trimester \\
15.03 & Eclampsia in pregnancy, third trimester \\
15.1 & Eclampsia in labour \\
15.2 & Eclampsia, in the puerperium \\
15.9 & Eclampsia, unspecified as to time period \\
\hline
\end{tabular}

